\title{
KAWASAN TUNGKU NAGA DI SAKKOK, SINGKAWANG DRAGON KILN HERITAGE SITE
}

\author{
Florensita Melly Muspita Sari \\ Program Studi Teknik Arsitektur Fakultas Teknik Universitas Lambung Mangkurat \\ florensitamelly@gmail.com
}

\author{
Naimatul Aufa \\ Program Studi Teknik Arsitektur Fakultas Teknik Universitas Lambung Mangkurat \\ naimatulaufa@ulm.ac.id
}

\begin{abstract}
ABSTRAK
Kawasan Sakkok di Singkawang dikenal sebagai penghasil keramik tradisional cina. Keramik-keramik tersebut dihasilkan melalui proses pembakaran pada sebuah tungku pembakaran tertutup yang disebut dengan Tungku Naga. Tungku Naga merupakan hasil teknologi dan budaya yang dibawa para imigran cina daratan, Tungku Naga yang masih aktif digunakan saat ini hanya tersisa di Singapura dan Sakkok Singkawang. Kota Singkawang berstatus sebagai Kota Pusaka Indonesia, sehingga kota ini diwajibkan untuk memberdayakan pusaka-pusakanya. Hal ini didukung oleh warga Kota Singkawang, salah satunya adalah pengrajin-pengrajin di Kawasan Tungku Naga. Sehingga permasalahan arsitektur yang diangkat dalam perancangan ini adalah "Bagaimana rancangan kawasan Tungku Naga yang memaksimalkan potensi Cultural Heritage (Pusaka Budaya) dalam rangka melestarikan Tungku Naga dan Industri Keramik Tradisional Cina?". Untuk menyelesaikan permasalahan tersebut adapun metode yang akan digunakan adalah Revitalisation Thinking. Revitalisation Thinking merupakan suatu metode penyelesaian masalah berbasis pada revitalisasi yang akan dilakukan secara bertahap, untuk memaksimalkan rancangan desain. Adapun konsep yang digunakan adalah Cultural Heritage Tourism yang edukatif, rekreatif dan berkelanjutan agar kawasan Tungku Naga yang mampu memaksimalkan potensi Cultural Heritage (Pusaka Budaya) melalui pengembangan potensi pariwisata dalam rangka melestarikan Tungku Naga dan Industri Keramik Tradisional Cina di Singkawang, Indonesia dan Asia Tenggara.

Kata kunci:Tungku Naga, Keramik Cina, Cultural Heritage, pelestarian, revitalisasi
\end{abstract}

\begin{abstract}
Sakkok area in Singkawang is notorious for its traditional Chinese ceramics industry. These ceramics are produced through a wood-firing process in a closed kiln called Dragon Kiln. Dragon Kiln is the product between culture and technology, which was brought by the Southern Chinese immigrants. The only remaining Dragon Kilns, that are still being used and fired now, are in Singapore and Sakkok, Singkawang. Singkawang city is enlisted as Indonesia's heritage city, therefore, the city is suggested to empower its heritages. This is supported by the people of Singkawang city, in which some of them are the crafters in the Dragon Kiln area. The highlighted architectural problem in this study is "How the architectural design of Dragon Kiln will maximize its Cultural Heritage potential in order to preserve the Dragon Kiln and Traditional Chinese Ceramics Industry?" The applied method for this study is Revitalization Thinking. Revitalization Thinking is a problem solving method based on revitalizing, done in stages, to maximize the design planning. The concept that is implied is an educative, recreational, and sustainable Cultural Heritage Tourism in order to maximize the Cultural Heritage potential of Dragon Kiln through the development of tourism in preserving the Dragon Kiln
\end{abstract}


and Traditional Chinese Ceramics Industry in Singkawang, Indonesia and South-east Asia.

Keywords: Dragon Kiln, Chinese Ceramics, Cultural Heritage, Preservation, Revitalization

\section{PENDAHULUAN}

Singkawang merupakan salah satu kota di Indonesia yang mayoritas penduduknya adalah Orang Tionghoa. Singkawang sendiri hingga sekarang masih terkenal dengan kebudayaan-kebudayaan asli masyarakat Tionghoa, salah satunya adalah perayaan Cap Go Meh, selain itu Singkawang juga terkenal dengan kuliner dan beberapa kerajinan tangannya seperti kain tenun, kerajinan kayu dan keramik tradisional Cina.

Kawasan Sakkok, Singkawang dikenal sebagai kawasan penghasil keramik, Keramik Tradisional Cina yang diproduksi di Sakkok, Singkawang, dari dulu hingga sekarang masih diproduksi secara tradisional. Proses produksi yang berawal dari pemecahan tanah kaolin, pencampuran tanah liat, pencampuran tanah liat dengan kaolin, pembentukan awal, penggabungan, dekorasi hingga proses glasir semua masih menggunakan tenaga manusia. Pada proses akhir produksi keramik yaitu pembakaran, hingga saat ini masih menggunakan Tungku Naga.

Tungku Naga yang aktif berproduksi di Asia Tenggara hanya tersisa di 2 (dua) lokasi, yaitu : di Singapura: Dragon Kiln, Thow Kwang Dragon Kiln Village, 85 Lor Tawas, Singapore 639823; dan di Indonesia (Sakkok, Singkawang): Pabrik Keramik Borneo Lentera Prima yang berada di Jl. Latsitarda, Kel. Sedau, Kec. Singkawang Selatan. Hal ini menjadikan Pabrik Borneo Lentera Prima (BLP) sebagai objek penting dalam sejarah keramik di Asia Tenggara, khususnya Indonesia.

Pemerintah Kota Singkawang telah mendaftarkan Tungku Naga Pabrik BLP sebagai cagar budaya/cultural heritage dengan nomor registrasi PO 2014101400022. Selain Pabrik BLP, terdapat 3 (tiga) pabrik keramik lain di Kota
Singkawang, yaitu: Pabrik Sinar Terang, Pabrik Tajau Mas dan Pabrik Dinamis. Dari 4 (empat) pabrik ini, hanya pabrik BLP dan pabrik Tajau Mas yang masih memiliki Tungku Naga, namun yang masih aktif memproduksi keramik dengan menggunakan Tungku Naga hanya pabrik

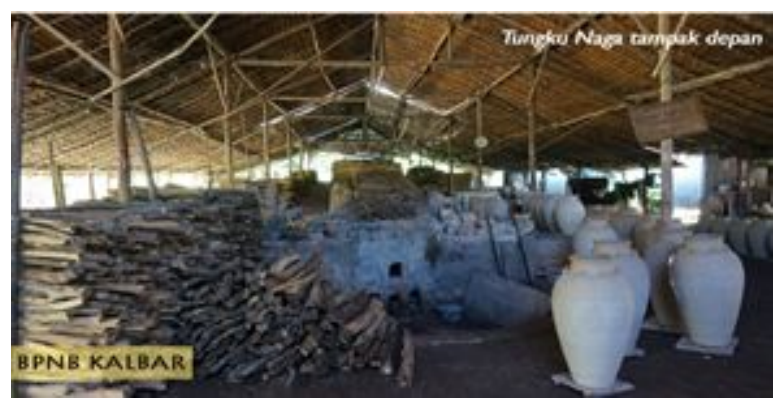

BLP.

Gambar 1. Tungku Naga BLP

Sumber: BPNP Kalbar (2020)

Program Kota Pusaka Singkawang untuk mendukung program Kota Wisata Pusaka Kalimantan Barat, didukung oleh warga Kota Singkawang, salah satunya adalah pengrajin-pengrajin di Kawasan Tungku Naga. Hasil wawancara dengan Bapak Ajung (pemilik pabrik BLP), beliau menginginkan pabrik BLP dikembangkan menjadi salah satu tujuan pariwisata Kota Singkawang agar industri keramik kembali berjaya, sehingga terjadi regenerasi pengrajin keramik, transfer pengetahuan, teknik dan material keramik Cina ke generasi berikutnya.

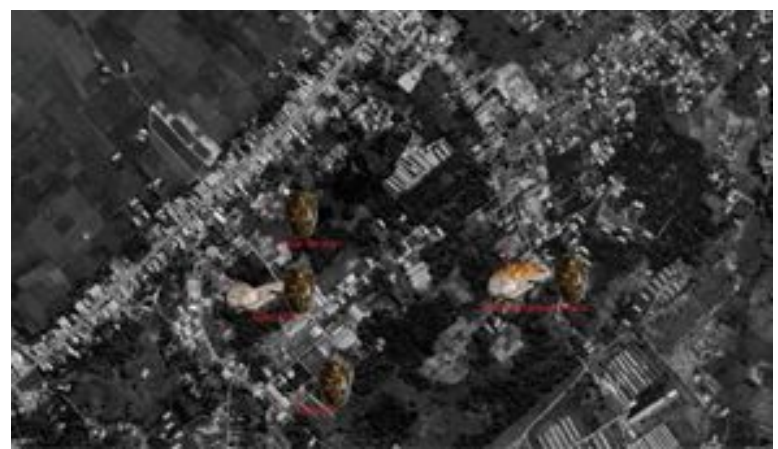

Gambar 2. Sebaran Pabrik Keramik dan Tungku Naga di Sakkok

Sumber: Analisis Pribadi (2020) 


\section{PERMASALAHAN}

Permasalahan arsitektural yang dirumuskan untuk memperoleh konsep dan rancangan kawasan Tungku Naga yaitu: "Bagaimana rancangan kawasan Tungku Naga yang memaksimalkan potensi Cultural Heritage dalam rangka melestarikan Tungku Naga dan Industri Keramik Tradisional Cina?".

\section{TINJAUAN PUSTAKA}

\section{A. Sejarah Industri Keramik Tradisional cina di Singkawang}

Keramik tradisional Cina di Sakkok, Singkawang memiliki sejarah yang cukup panjang. Awal mula keramik-keramik Cina ini sampai ke Singkawang dimulai pada saat Pertambangan emas sedang populer di Kerajaan Sambas dan Mempawah.

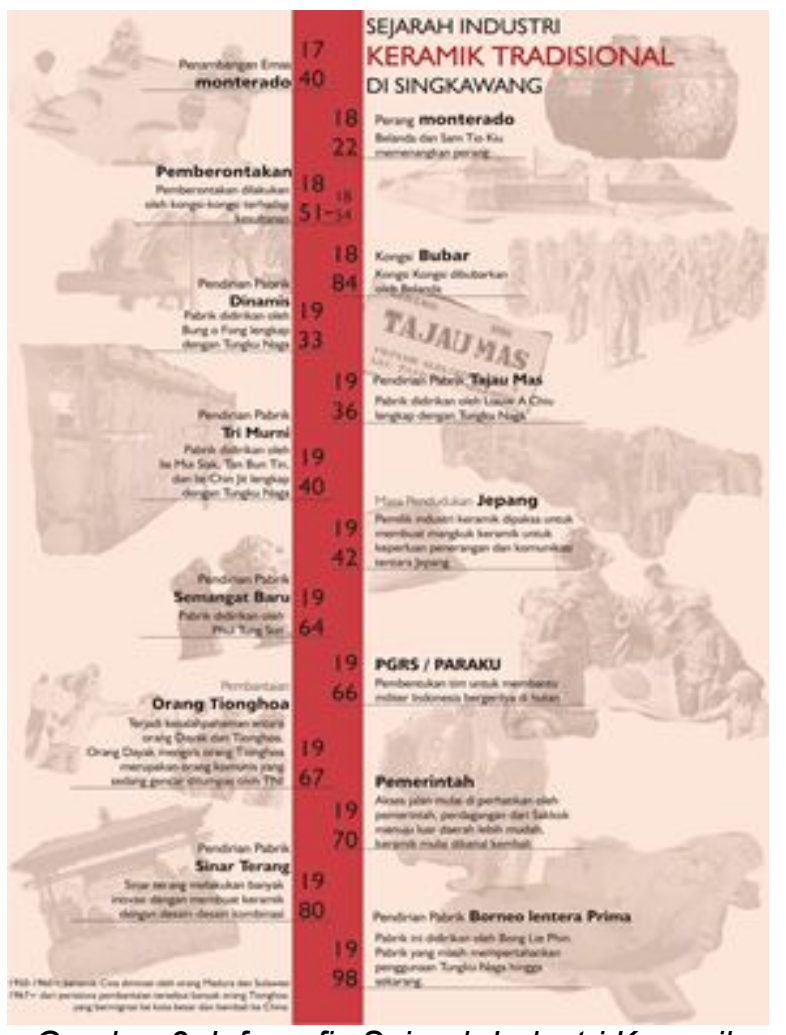

Gambar 3. Infografis Sejarah Industri Keramik Tradisional Cina di Sakkok

Sumber: Buku Dinamika Industri Keramik

Tradisional Cina di Sakkok Kota Singkawang Tahun 1993 Sampai 2008-Diolah Kembali oleh Penulis (2020)

\section{B. Tungku Naga}

Tungku naga merupakan tungku pembakaran tradisional yang berasal dari Cina, lebih tepatnya dari daerah Guangdong, wilayah Cina selatan. Dahulu, masyarakat disana belum ada yang mengenal namanya tungku untuk membakar produk keramik mereka. Para pengrajin hanya memanfaatkan gua-gua di sekitar pegunungan untuk difungsikan sebagai ruang pembakaran. Tungku dibuat sedemikian rupa "menyerupai" bentuk seekor naga, bentuknya panjang memiliki mata dan mulut, dulu pengrajin-pengrajin keramik Cina memanfaatkan gua di bagian depannya (kepala) lebih tepatnya di bagian mulut tempat mereka memasukkan kayu, di bagian tengahnya (perut) dimasukkan keramik-keramik yang akan dibakar, di bagian belakang (ekor) merupakan tempat keluar asap hasil pembakaran tersebut. Tungku Naga bisa mencapai suhu hingga $1250^{\circ}$ Celcius, waktu pembakarannya memakan hingga 24 jam dan api yang dibakar harus dijaga terus menerus tidak boleh sampai mati. Keramik-keramik yang dibakar dengan Tungku Naga memiliki efek spesial yang tidak dapat dihasilkan oleh hasil pembakaran menggunakan tungku pembakaran biasa maupun oven listrik.

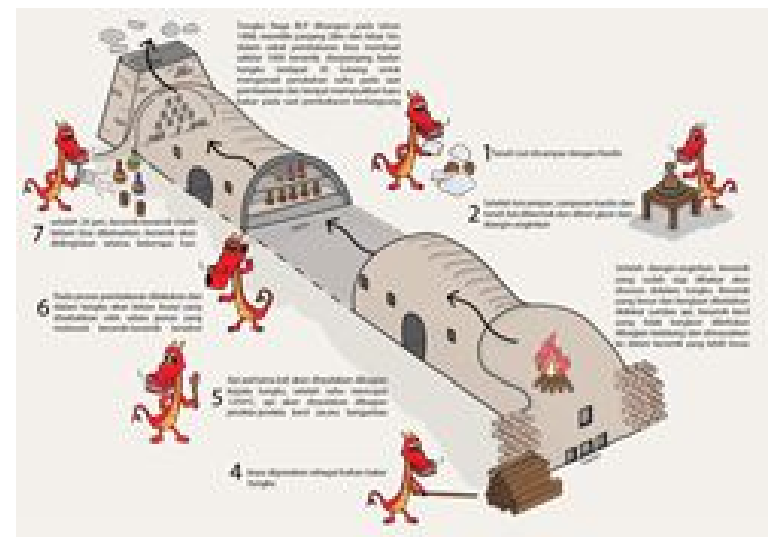

Gambar 4. Informasi Umum Tentang Tungku Naga

Sumber: Thow kwang Pottery Jungle-Diolah Kembali oleh Penulis (2020) 


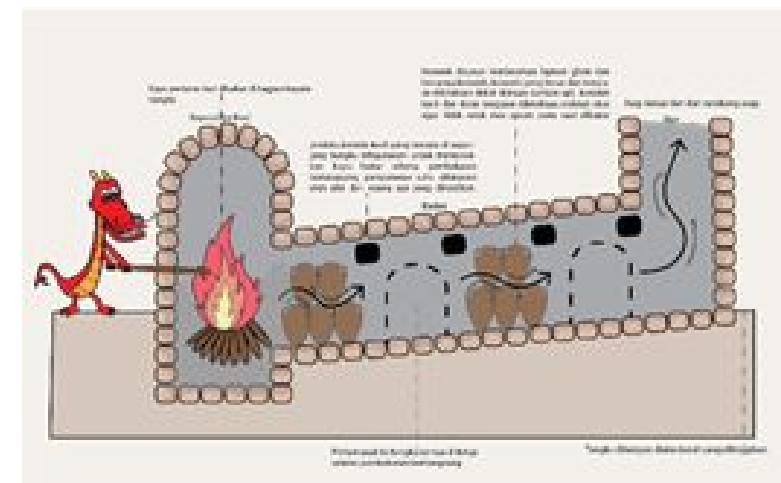

Gambar 5. Pembakaran Melalui Tungku Naga Sumber: Thow kwang Pottery Jungle- Diolah Kembali oleh Penulis (2020)

\section{Tinjauan Konsep}

Pariwisata pusaka budaya adalah sebuah kegiatan wisata untuk menikmati berbagai adat istiadat lokal, benda-benda cagar budaya, dan alam beserta isinya di tempat asalnya yang bertujuan untuk memberikan pengetahuan dan pemahaman akan keanekaragaman budaya dan alam bagi pengunjungnya. World Tourism Organization (WTO) mencatat bahwa pusaka (heritage) dan budaya (culture) telah menjadi komponen dalam $40 \%$ perjalanan internasional yang dilakukan. (Patria, 2015).

Beberapa lembaga telah mendefinisikan cultural heritage tourism dengan titik berat yang berbeda-beda:

1) Organisasi Wisata Dunia (World Tourism Organization) mendefinisikan pariwisata pusaka budaya sebagai kegiatan untuk menikmati sejarah, alam, peninggalan budaya manusia, kesenian, filosofi dan pranata dari wilayah lain.

2) Badan Preservasi Sejarah Nasional Amerika (The National Trust for Historic Preservation) mengartikannya sebagai perjalanan untuk menikmati tempat-tempat, artefak-artefak dan aktifitas-aktifitas yang secara otentik mewakili cerita/sejarah orang-orang terdahulu maupun saat ini.

3) Commonwealth of Australia, Creative Nation mendefinisikannya sebagai seluruh pengalaman yang dapat dirasakan oleh pengunjung,apa yang membuat destinasi tersebut spesial, bisa jadi gaya hidup masyarakatnya, benda pusakanya, seninya, masyarakat lokalnya dan sebuah bisnis yang memprovide dan memfasilitasi budaya tersebut kepada pengunjung.

Pariwisata Pusaka Budaya kini menjadi salah satu segmen industri pariwisata yang perkembangannya paling pesat, dikarenakan oleh adanya tren baru bagi wisatawan untuk mencari sesuatu yang unik dan otentik dari suatu budaya, apabila pariwisata pusaka budaya dikelola dan dimanfaatkan dengan tepat, tidak menutup kemungkinan pariwisata dalam sektor ini dapat menjadi sumber pendapatan daerah yang dapat mendorong pertumbuhan perekonomian.

\section{METODE}

Revitalisasi kawasan dengan menambah fungsi pariwisata merupakan cara yang paling populer untuk dikembangkan dalam menata kawasan yang bernilai sejarah dan budaya, karena kawasan tersebut sudah memiliki keunikan sejarah dan budaya sehingga dapat mendatangkan nilai pariwisata. Untuk mewujudkan kawasan dengan nilai sejarah, budaya dan pariwisata, maka diperlukan sebuah proses berpikir desain dengan metode revitalisasi kawasan.

Merancang kawasan dengan metode revitalisasi dimulai dari riset data-data sejarah mengenai benda cagar budaya dan kawasan yang akan dirancang. Kemudian dilanjutkan dengan proses perancangan 
kawasan dan arsitektur tujuan perancangan tercapai. Proses ini disebut dengan metode Revitalisation Thinking, yaitu metode pendekatan berbasis revitalisasi dengan cara bertahap. Berikut adalah tahapan riset dan perancangan kawasan dengan metode Revitalisation Thinking:

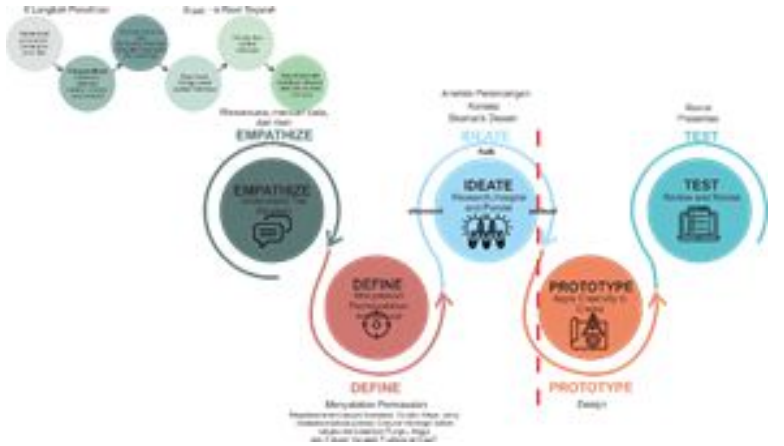

Gambar 6. Infografik Revitalisation Thinking Sumber: Analisis Pribadi (2020)

\section{PEMBAHASAN}

\section{A. Lokasi}

Kawasan Tungku Naga yang akan direncanakan berada di sepanjang jalan Latsitarda, desa Sakkok, kecamatan Sedau, Singkawang, Kalimantan Barat. Lokasi site berada disepanjang jalan Latsitarda dengan panjang sekitar $700 \mathrm{~m}$ yang dapat diakses dari Jalan A.yani. Kawasan ini dapat ditempuh 15 menit dari pusat kota Singkawang dan 3 jam dari Pusat Kota Pontianak. Pabrik Borneo Lentera Prima dan Tungku Naga terletak pada ujung kawasan.
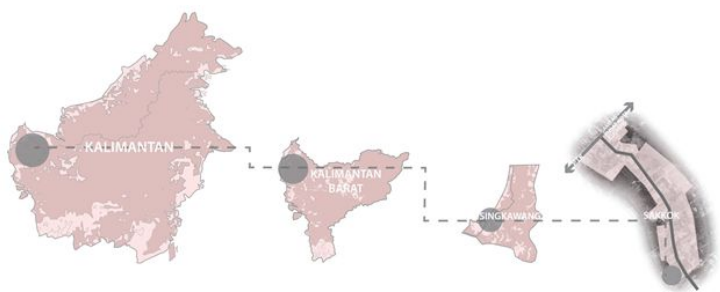

Gambar 7. Lokasi Kawasan Sumber: Analisis Pribadi (2020)

\section{B. Konsep Programatik}

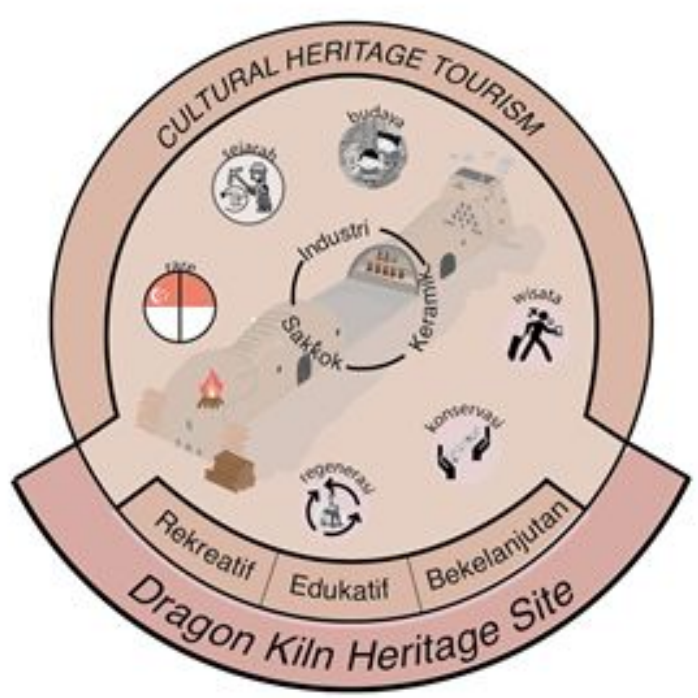

Gambar 8. Diagram Konsep Program Sumber: Analisis Pribadi (2020)

Cultural Heritage Tourism
Konsep program yang akan
dirumuskan untuk menyelesaikan
permasalahan:" Bagaimana rancangan
kawasan Tungku Naga yang
memaksimalkan potensi Cultural Heritage
(Pusaka Budaya) dalam rangka
melestarikan Tungku Naga dan Industri
Keramik Tradisional Cina?" adalah Cultural
Heritage Tourism yang edukatif, rekreatif,
dan berkelanjutan. Cultural Heritage Tourism
merupakan sebuah kegiatan wisata untuk
menikmati berbagai adat istiadat lokal,
benda cagar budaya, dan alam beserta
isinya di tempat asalnya yang bertujuan
untuk memberikan pengetahuan dan
pemahaman akan keanekaragaman budaya
dan melakukan interaksi sosial antara warga
dan pengunjung yang datang serta
berkelanjutan untuk kedepannya. Dengan
diangkatnya konsep programatik ini
diharapkan bisa memberikan dampak yang
positif kepada warga dan khususnya kepada
Tungku Naga dan Industri Keramik
Tradisional Cina.

\section{Konsep Desain}

\section{Konsep Kawasan}

Konsep Kawasan yang digunakan merupakan interpretasi dari sebuah naga 
yang terdiri dari 3 bagian yaitu kepala sebagai area penerimaan, badan sebagai area rekreasi, dan ekor sebagai area inti.

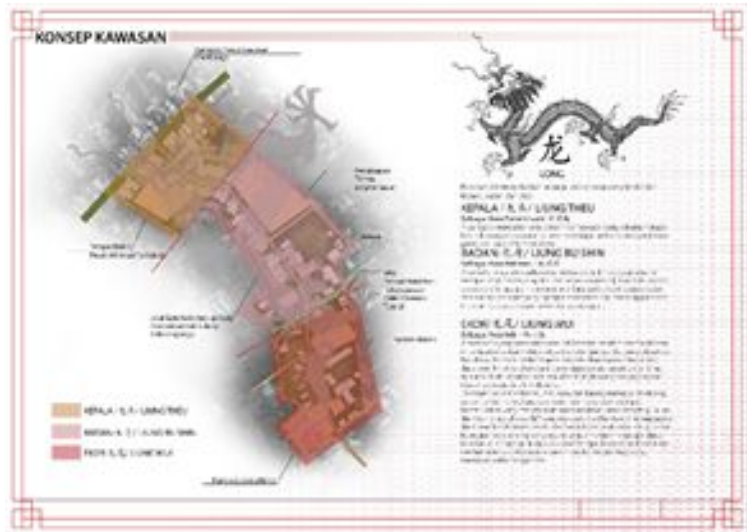

Gambar 9. Konsep Kawasan

Sumber: Analisis Pribadi (2020)

2. Konsep Bentuk Bangunan

Mengadaptasi bentuk SiHeYuan yang merupakan rumah tradisional Cina yang masih digunakan prinsipnya hingga sekarang, membuat grid untuk melayout kawasan dan ruang-ruang yang akan direncanakan ,menggunakan bahan bangunan lokal dan membuat ukiran yang dapat menjadi ciri khas kawasan.

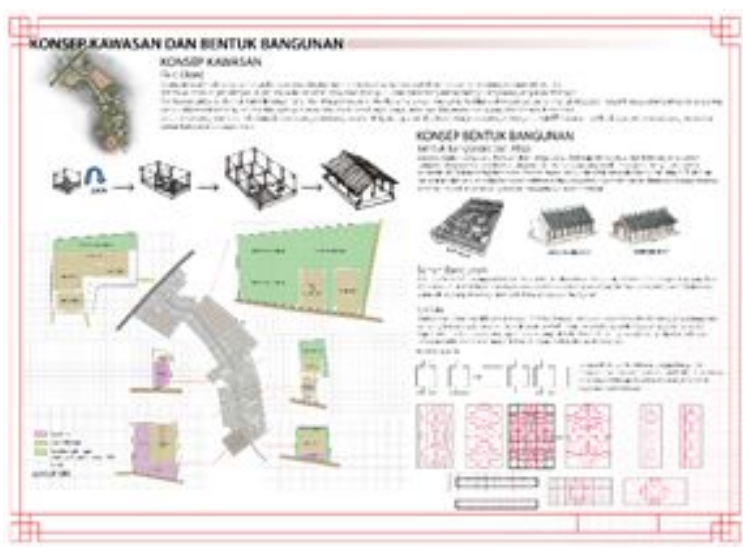

Gambar 10. Konsep Bentuk Bangunan Sumber: Analisis Pribadi (2020)

HASIL

\section{A. Aerial View}

View beberapa bagian kawasan jika dilihat dari ketinggian.

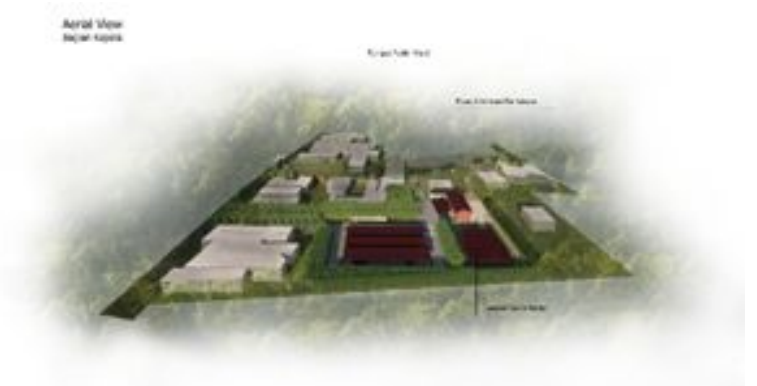

Gambar 11. Aerial View Bagian Kepala Sumber: Analisis Pribadi (2020)

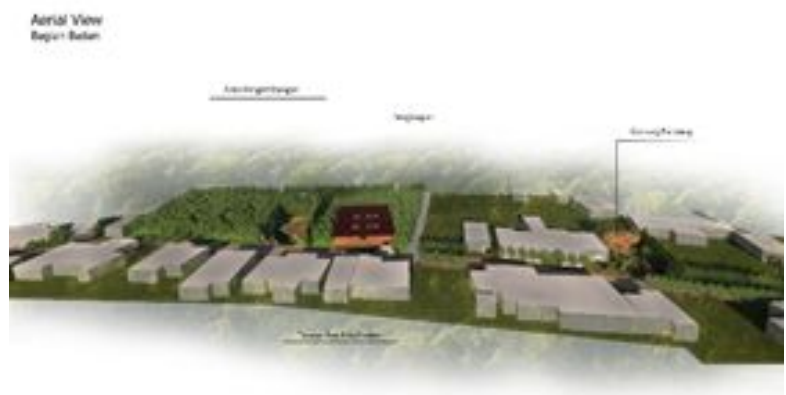

Gambar 12. Aerial View Bagian Badan Sumber: Analisis Pribadi (2020)

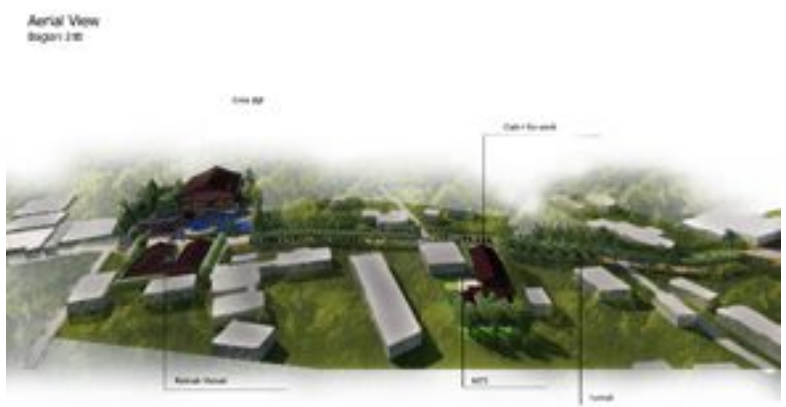

Gambar 13. Aerial View Bagian Ekor Sumber: Analisis Pribadi (2020)

\section{B. Gerbang}

Gerbang menggunakan konsep gerbang cina pada suatu Kawasan yang membedakan pada Kawasan ini adalah kolom pada gerbang ini menggunakan lapisan batu bata yang disusun memutar keatas. 


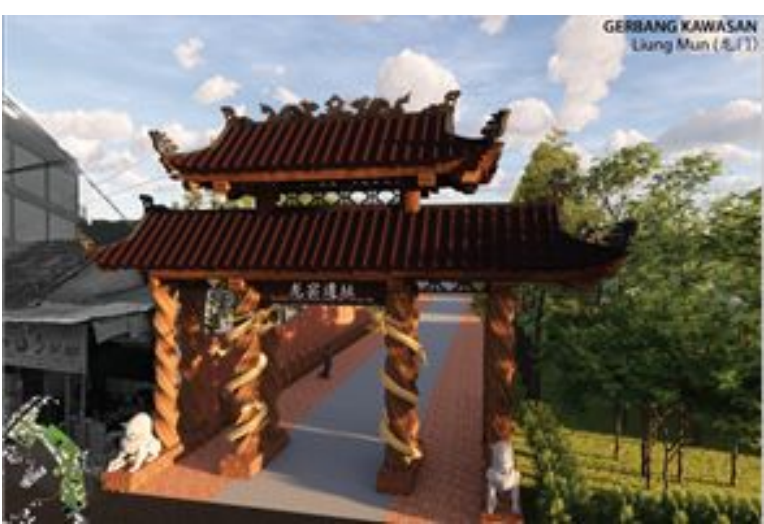

Gambar 14. Gerbang Utama Kawasan Sumber: Analisis Pribadi (2020)

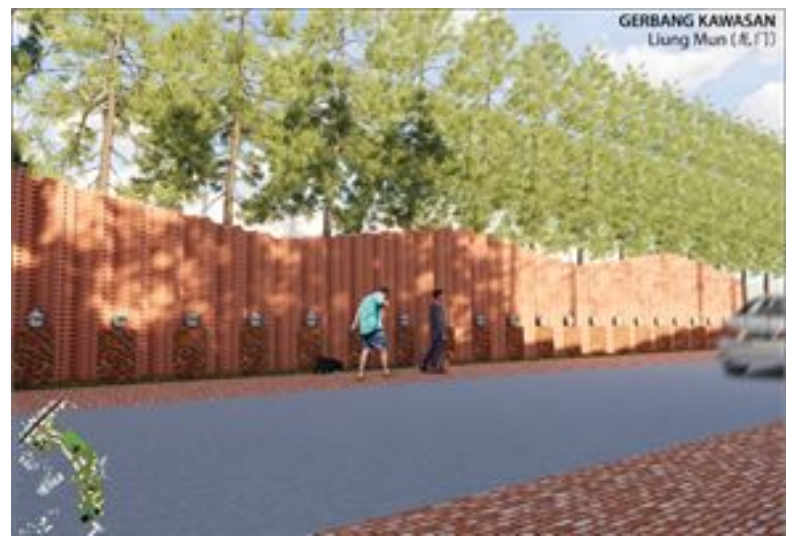

Gambar 15. Dinding Gerbang Sumber: Analisis Pribadi (2020)

\section{Area Parkiran dan Pusat Informasi}

\section{Pariwisata}

Membuat beberapa aturan tentang sirkulasi kawasan dan menyediakan lahan parkir terpadu untuk warga dan pengunjung.

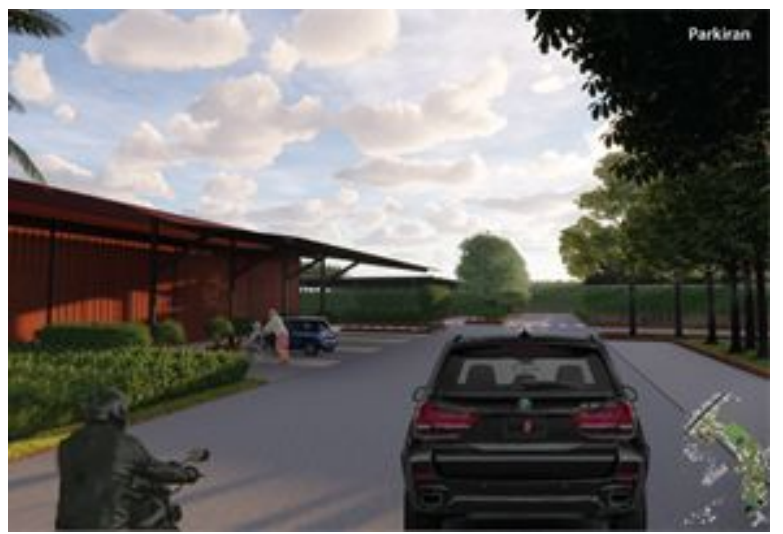

Gambar 16. Parkiran

Sumber: Analisis Pribadi (2020)

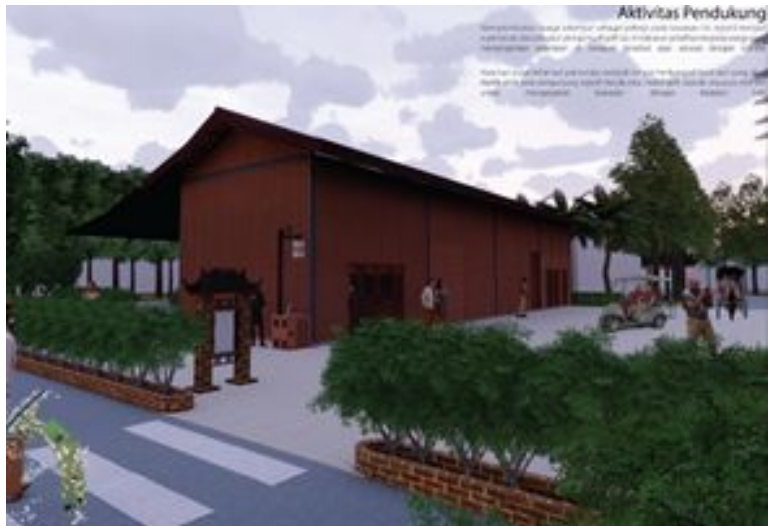

Gambar 17. Pusat Informasi Pariwisata Sumber: Analisis Pribadi (2020)

\section{Street Furniture}

Beberapa street furniture yang akan berada di sepanjang jalan kawasan Tungku Naga

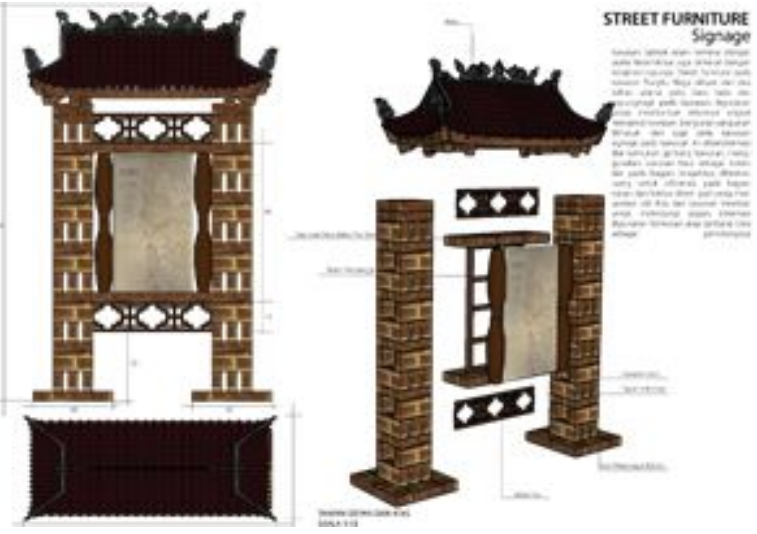

Gambar 18. Signage

Sumber: Analisis Pribadi (2020)
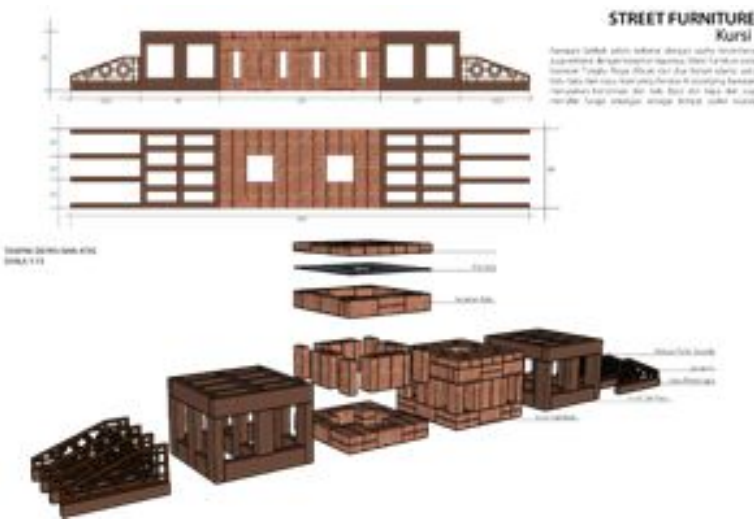

Gambar 19. Kursi

Sumber: Analisis Pribadi (2020) 


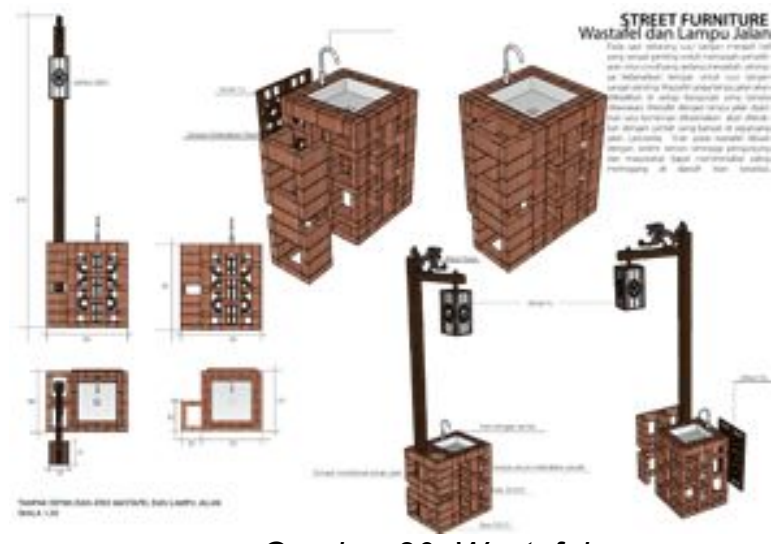

Gambar 20. Wastafel

Sumber: Analisis Pribadi (2020)
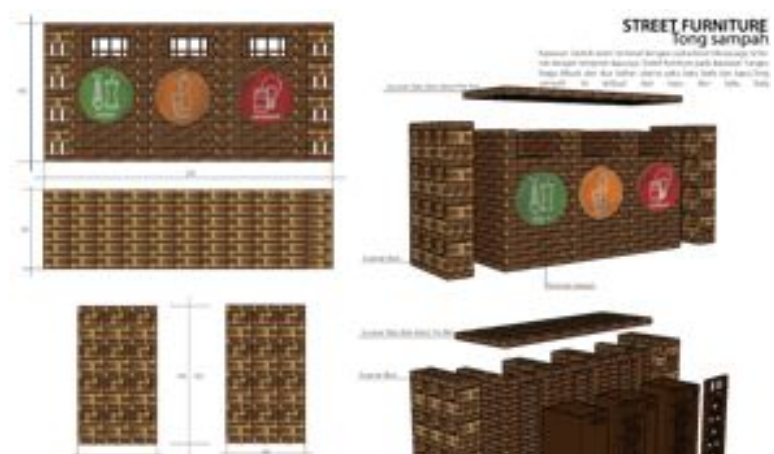

Gambar 21. Tong Sampah

Sumber: Analisis Pribadi (2020)

\section{E. Penginapan}

Bangunan penginapan mengadaptasi bentuk SiHeYuan dan disusun dengan grid.

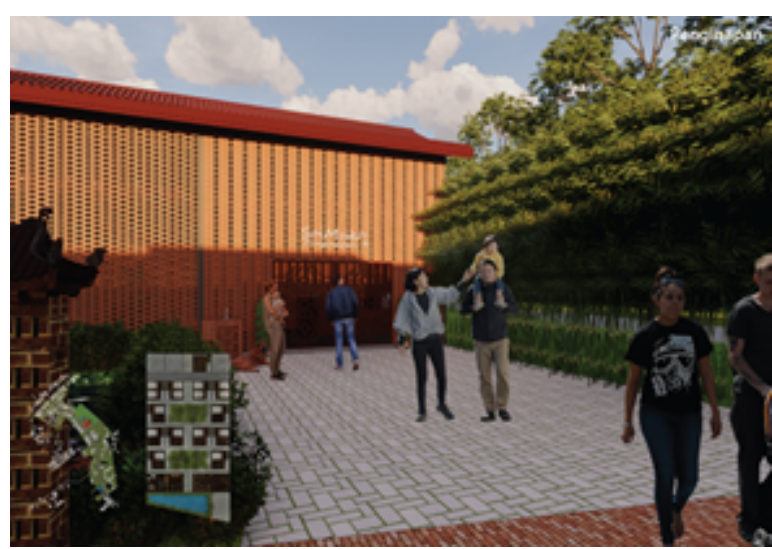

Gambar 22. Penginapan

Sumber: Analisis Pribadi (2020)

\section{F. Taman dan Amphitheater}

Tempat dimana acara kebudayaan, permainan tradisional dan puncak event-event kebudayaan akan diadakan.

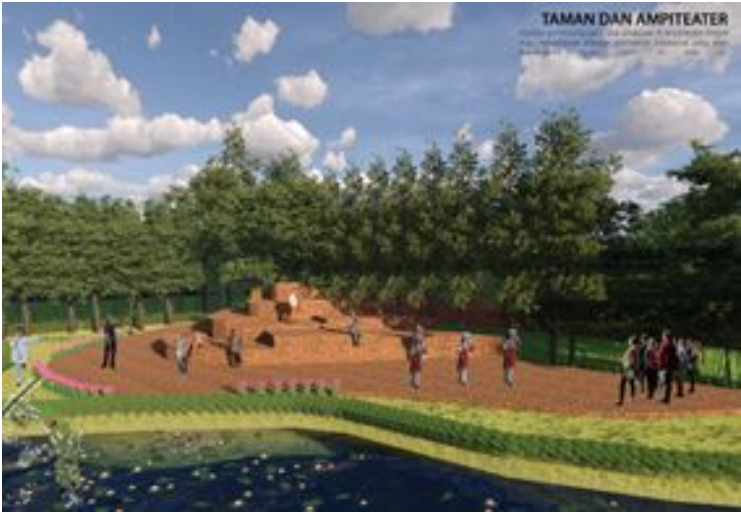

Gambar 23. Taman dan Amphitheater

Sumber: Analisis Pribadi (2020)

\section{G. Gunung Pandang}

Taman yang memiliki sebuah gunung buatan untuk bermain dan melihat pemandangan disekitar kawasan.

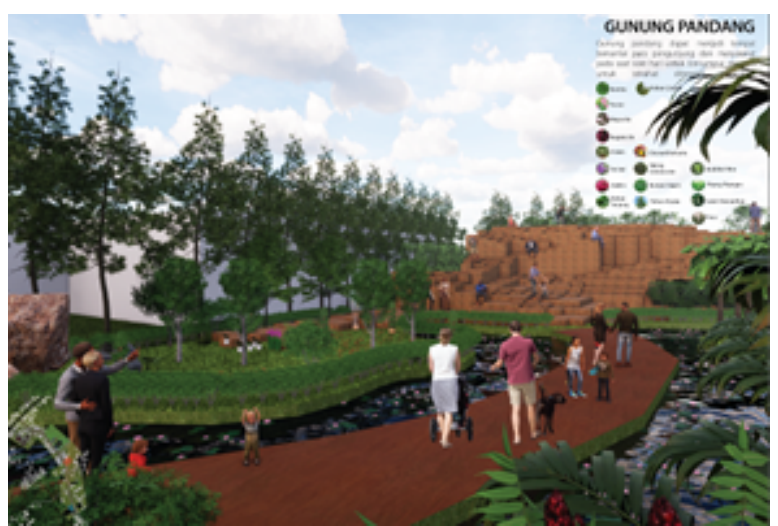

Gambar 24. Gunung Pandang

Sumber: Analisis Pribadi (2020)

\section{H. Tunnel}

Terowongan dibuat menyerupai dengan Bagian dalam tambang emas dan bagian dalam Tungku Naga bedanya terowongan di Kawasan ini tidak dibuat masif agar cahaya matahari dapat masuk kesela lubang-lubang terowongan. 


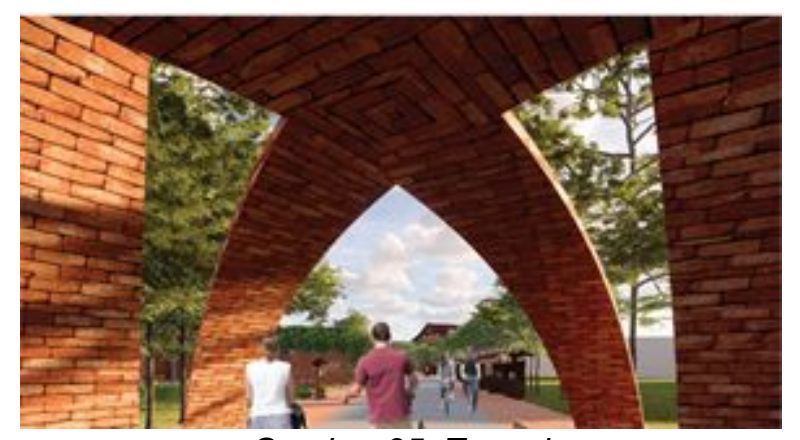

Gambar 25. Tunnel

Sumber: Analisis Pribadi (2020)

\section{Galeri dan Mes}

Pada Galeri akan memberikan informasi tentang sejarah masuknya orang cina ke Indonesia serta, serta sejarah industri keramik tradisional cina serta pameran keramik. Mes digunakan sebagai tempat tinggal dan pelatihan para pekerja BLP.

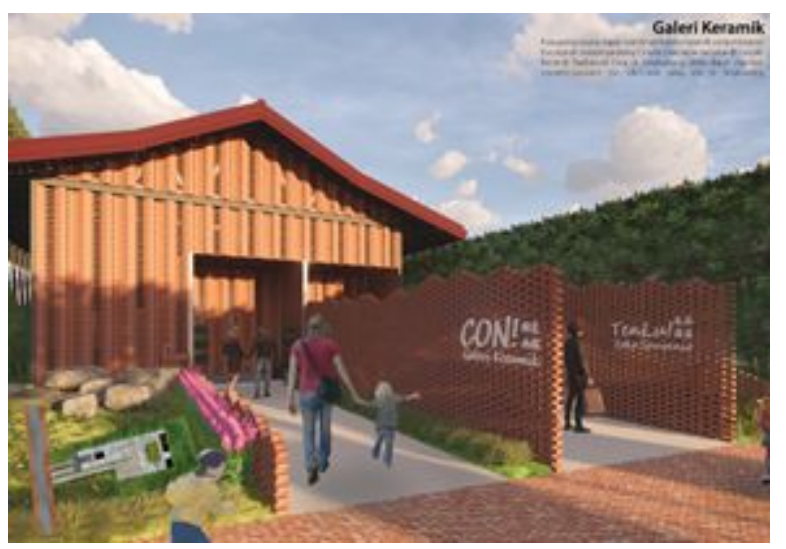

Gambar 26. Galeri Keramik Sumber: Analisis Pribadi (2020)

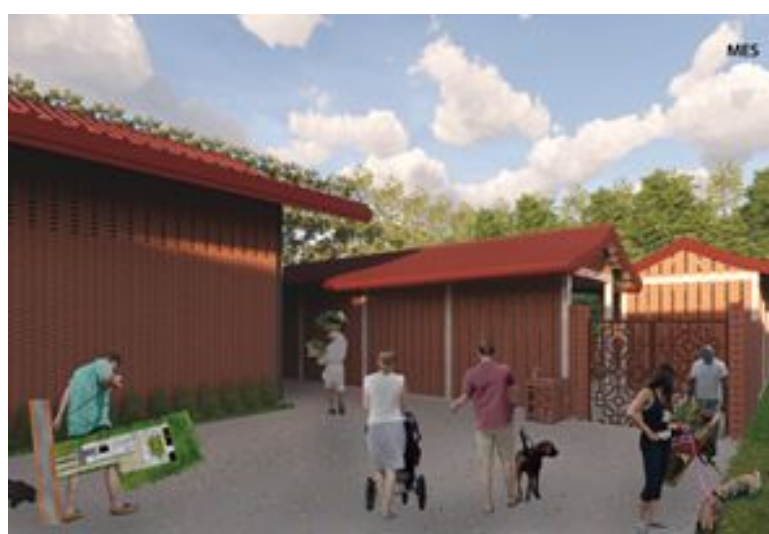

Gambar 27. Mes

Sumber: Analisis Pribadi (2020)

\section{J. Rumah Makan}

Menjual makanan berat khas Kalimantan Barat.

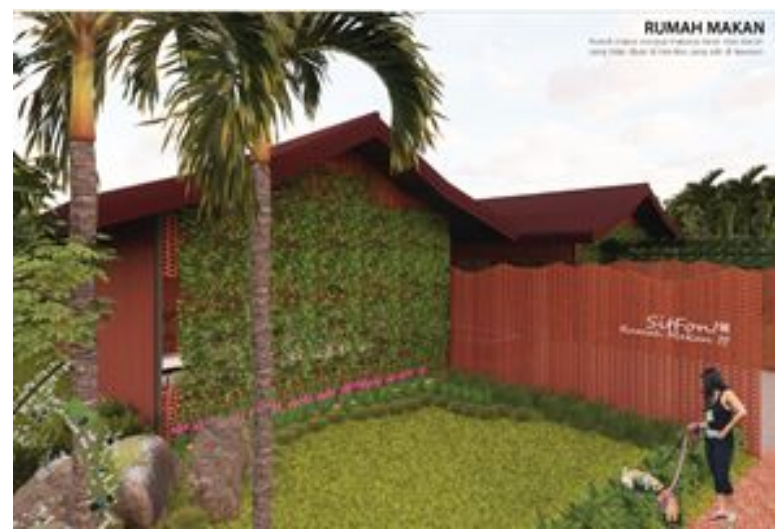

Gambar 28. Perspektif Mata Burung Sumber: Analisis Pribadi (2020)

\section{K. Borneo Lentera Prima (BLP)}

BLP merupakan area utama dari Kawasan ini, dimana Tungku Naga berada dan tempat produksi keramik di Kawasan ini bertempat. Ramp yang ada pada bangunan ini berguna sebagai jalan masuk dan Menara pandang, selain itu melalui ramp ini pengunjung dapat melihat proses pembuatan keramik dari beberapa view yang berbeda karena ramp dibuat menembus bangunan utama.Fasade pada BLP dapat diputar hingga 90 derajat untuk membantu sirkulasi udara didalamnya.

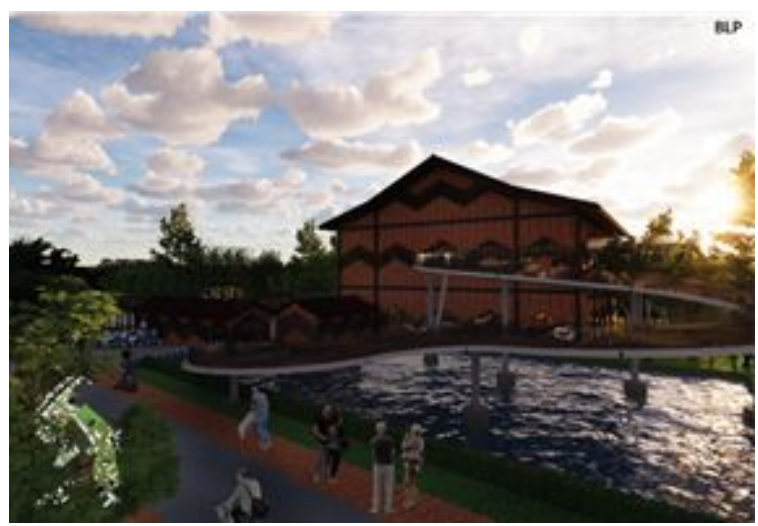

Gambar 29. BLP

Sumber: Analisis Pribadi (2020) 


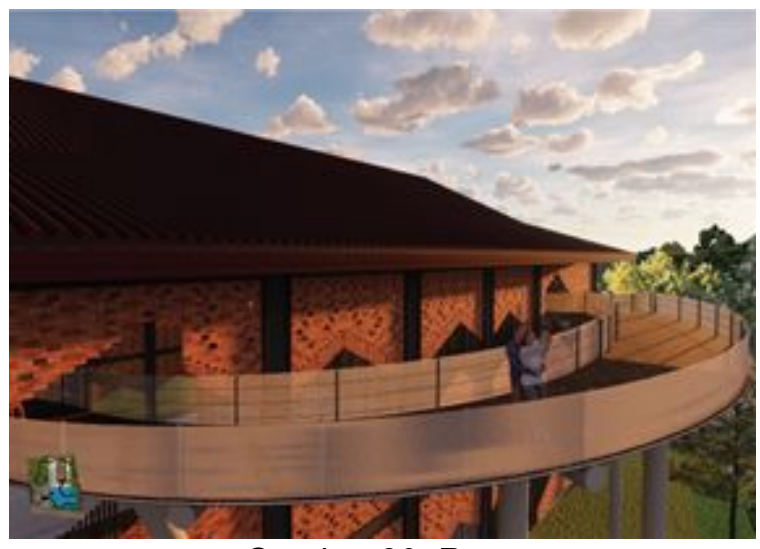

Gambar 30. Ramp

Sumber: Analisis Pribadi (2020)

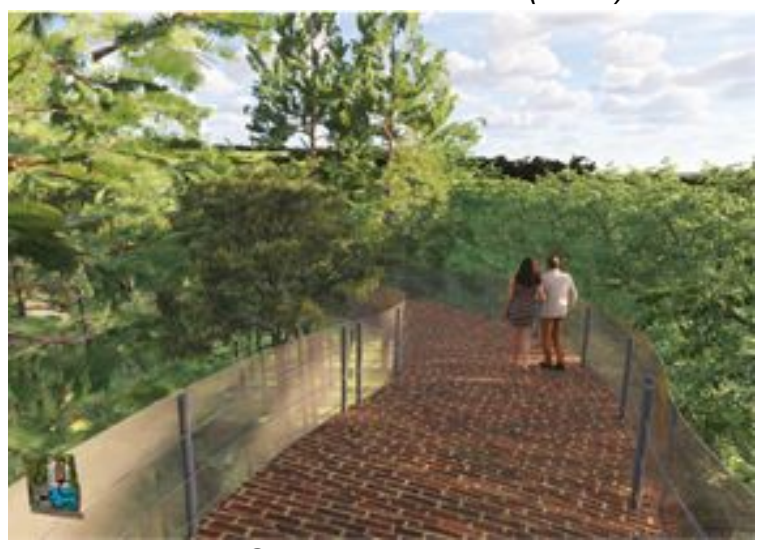

Gambar 31. Ramp

Sumber: Analisis Pribadi (2020)

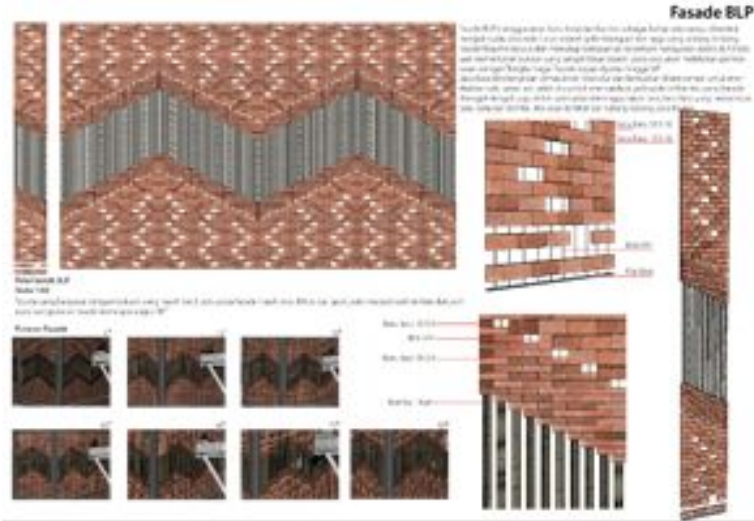

Gambar 32. Fasade

Sumber: Analisis Pribadi (2020)

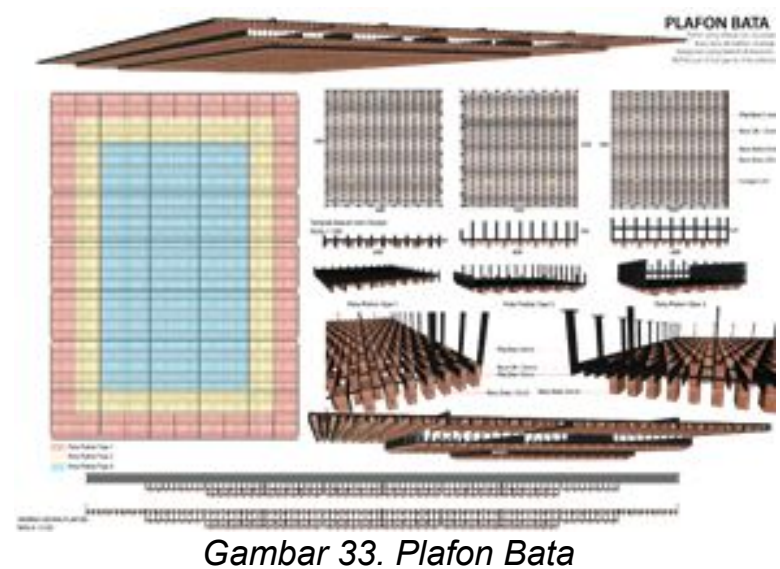

Sumber: Analisis Pribadi (2020)

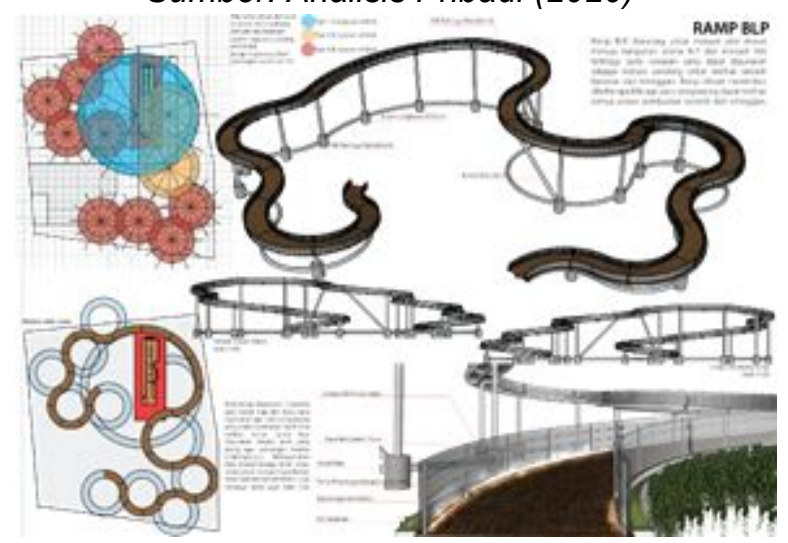

Gambar 34. Ramp

Sumber: Analisis Pribadi (2020)

\section{Aktivitas Pendukung}

Aktivitas pendukung pada Kawasan ini juga membantu Kawasan dapat dijalankan secara mandiri oleh masyarakat yang didapatkan dari studi-studi potensial pada masyarakat.Seperti acara-acara yang akan dilaksanakan pada saat event-event cina tiap tahunnya seperti imlek. warkop yang akan dibuka di halaman para warga yang ingin memiliki bisnis, dan juga area kios tempat dimana warga dapat berjualan makanan dan minuman khas Singkawang 


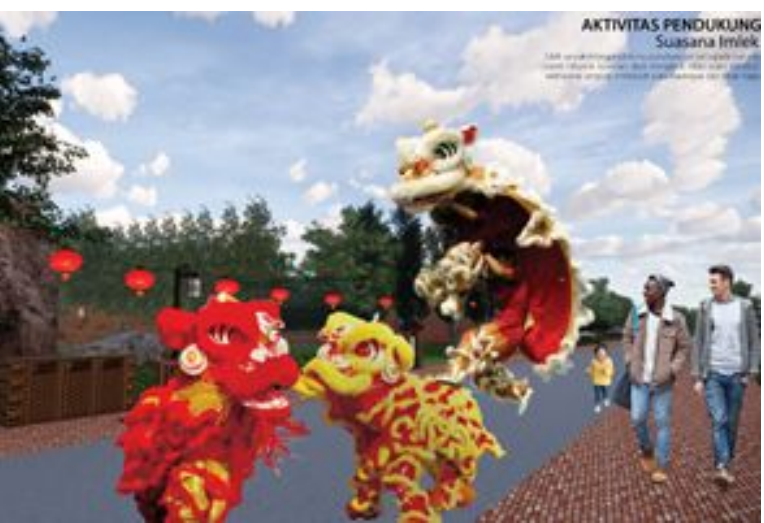

Gambar 35. Suasana Event Tahunan Sumber: Analisis Pribadi (2020)

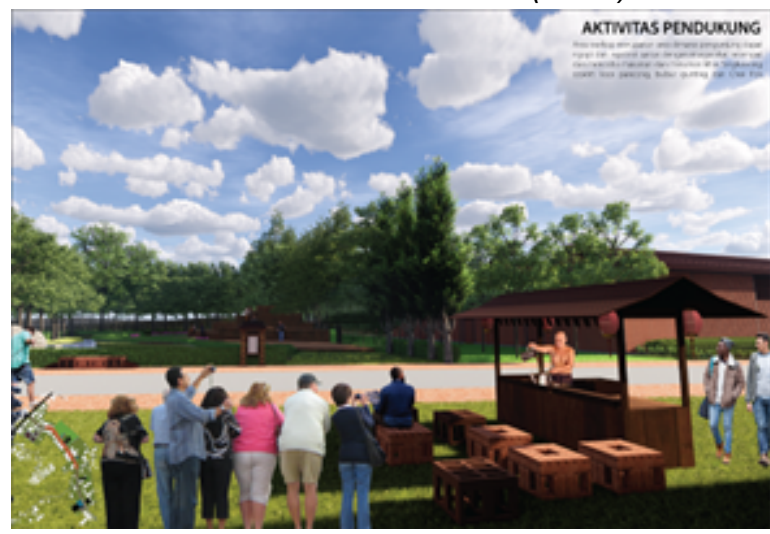

Gambar 36. Warkop

Sumber: Analisis Pribadi (2020)

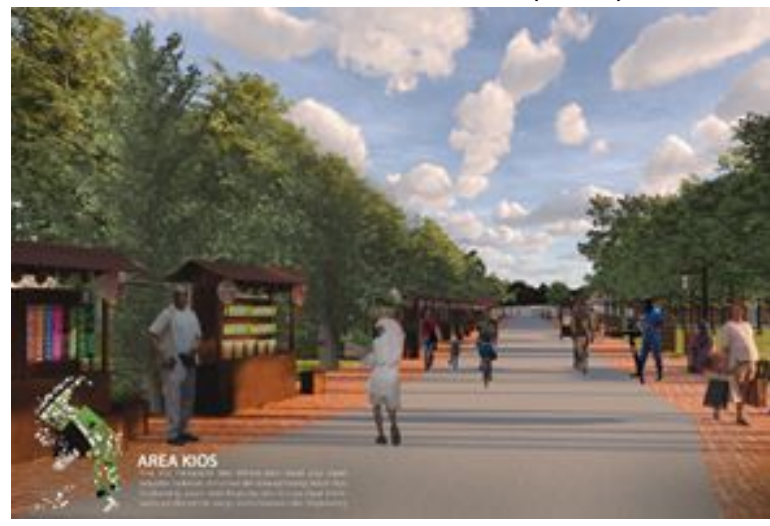

Gambar 37. Area Kios

Sumber: Analisis Pribadi (2020)

\section{Detail Dinding}

Detail arsitektural dinding-dinding bangunan yang berada di Kawasan Tungku Naga.

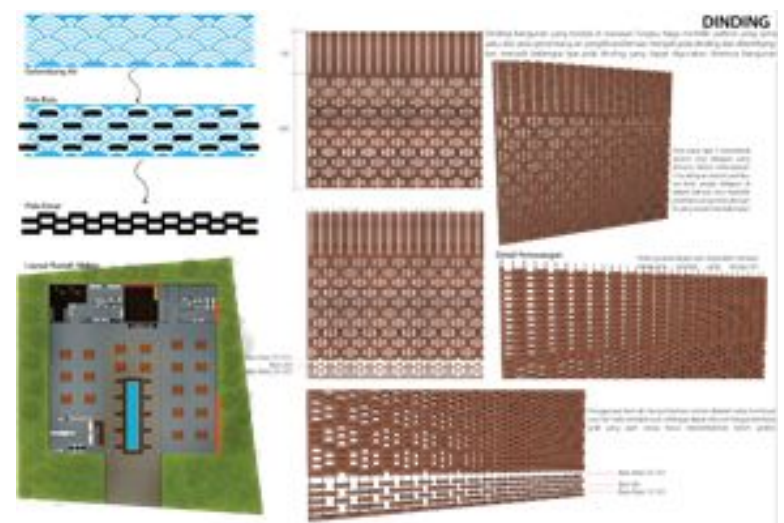

Gambar 38. Pola Dinding Sumber: Analisis Pribadi (2020)
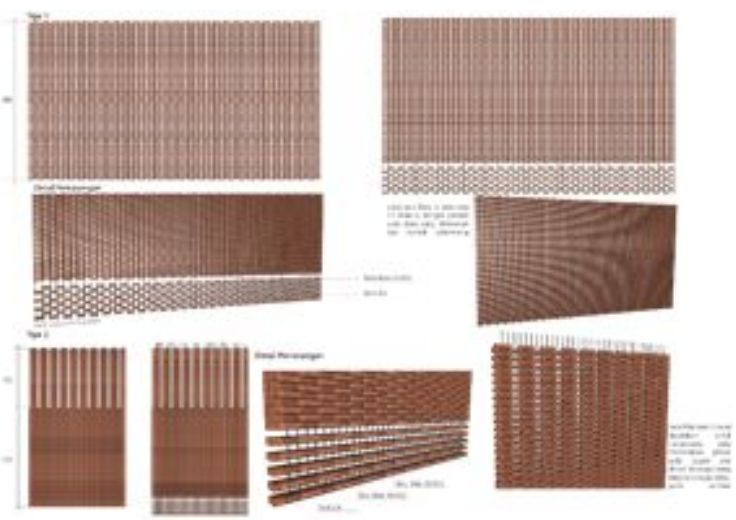

Gambar 39. Pola Dinding

Sumber: Analisis Pribadi (2020)

\section{KESIMPULAN}

Permasalahan dalam perancangan Kawasan Tungku Naga di Sakkok Singkawang adalah Bagaimana rancangan kawasan Tungku Naga yang memaksimalkan potensi Cultural Heritage (Pusaka Budaya) dalam rangka melestarikan Tungku Naga dan Industri Keramik Tradisional Cina. Melalui proses analisis, maka disimpulkan bahwa Kawasan Tungku Naga memerlukan konsep yang mampu membuat Tungku Naga kembali beroperasi seperti dulu. Konsep yang ditawarkan dalam perancangan ini adalah Cultural Heritage Tourism (CHT) yang edukatif, rekreatif dan berkelanjutan. Konsep ini diwujudkan ke dalam desain dengan metode Revitalisation Thinking. Melalui metode ini, didapat konsep desain sebagai berikut: 
1.Cultural Heritage Tourism yang edukatif melalui desain Galeri Keramik dan redesign Borneo Lentera Prima. CHT pada kawasan ini akan memberikan edukasi melalui pengalaman sejarah Industri Keramik Tradisional Cina di Sakkok-Singkawang. Selain itu, CHT pada kawasan ini juga akan memberikan pengalaman tentang proses produksi melalui workshop pembuatan keramik.

2.Cultural Heritage Tourism yang rekreatif melalui pengembangan daya tarik wisata dan peningkatan amenitas wisata sesuai dengan Permenpar No. 3 Tahun 2018 tentang DAK Fisik Bidang Pariwisata melalui desain kawasan yang berkarakter khas kawasan produksi industri keramik cina, seperti penggunaan tektonika bata merah produksi tungku naga, desain taman cina dan bangunan style Cina.

3.Cultural Heritage Tourism yang berkelanjutan melalui desain aktivitas pendukung melalui studi potensi-potensi yang dimiliki oleh masyarakat lokal agar aktivitas yang direncanakan dapat dilaksanakan secara mandiri oleh masyarakat lokal

Melalui perancangan Kawasan Tungku Naga dengan konsep Cultural Heritage Tourism yang edukatif, rekreatif dan berkelanjutan, potensi Cultural Heritages yang ada di kawasan Tungku Naga terlestarikan, khususnya untuk Tungku Naga serta Industri Keramik Tradisional Cina di Singkawang

\section{DAFTAR PUSTAKA}

\section{Referensi Buku dan Jurnal}

Ani Rahmayani, S. (2009). Dinamika Industri Keramik Cina di Sakkok Kota Singkawang Tahun 1933 Sampai Tahun 2008. Pontianak: Departemen Kebudayaan dan Pariwisata.

Arch G WoodSide, D. M. (2008). Tourism Management : Analysis, Behaviour and Strategy. CAB International.

Ashworth, G. (2000). Heritage Tourism and Urban Environments: Conflict or Harmony. Netherlands.
Danisworo, Martokusumo. (2002). Revitalisasi Kawasan Kota: Sebuah Catatan Dalam Pengembangan dan Pemanfaatan Kawasan Kota.

Harryman Idram, Antony S.Runtu, Rasmin, Mirza, Heru S.H.P. (1990). Pameran Khusus "Keramik Kontemporer Kalimantan Barat". Pontianak: Departemen Pendidikan dan Kebudayaan Kantor Wilayah Provinsi Kalimantan Barat.

Huib Akihary, N. P. (2016). Digging4Data. jakarta.

Nurhadi Rangkuti, Inge Pojoh, Nanik Harkantiningsih. (2008). Buku Panduan Analisis Keramik. Jakarta: Pusat Penelitian dan Pengembangan Arkeologi Nasional.

Patria, T. A. (2015). Dinamika Perkembangan Pariwisata Pusaka : Tinjauan dari Sisi Penawaran dan Permintaan di Kota Bandung. Binus Business, 169-183.

Triono, T. (2018). Singkawang Heritage. Singkawang: Dinas Pendidikan dan Kebudayaan Kota SIngkawang.

Wahyuri, N. (2013). Keramik Singkawang Kalimantan Barat. Jurnal Pendidikan Seni Kerajinan - S1 (E-Craft). Vol 2, No 1

B Alokasi Khusus Fisik Bidang Pariwisata.

Beberapa peraturan perundangan yang digunakan:

Piagam Pelestarian Pusaka Indonesia(2003)

UU Nomor 11 Tahun 2010 tentang Cagar Budaya

Undang-Undang nomor 26 tahun 2007 tentang Penataan ruang dalam melindungi Kota Pusaka yang tersebar di Indonesia PERDA Singkawang No.1 Tahun 2014 tentang Rencana Tata Ruang Wilayah Kota Singkawang untuk kawasan pariwisata

Peraturan Menteri Pariwisata Republik Indonesia No.3 Tahun 2018 Tentang Petunjuk Operasional Pengelolaan Dana Alokasi Khusus Fisik Bidang Pariwisata. 